\title{
Hydrogen-assisted fatigue crack growth in ferritic steels - a fractographic study
}

\author{
$D i$ Wan $^{1, *}$, Antonio Alvaro ${ }^{2}$, Vigdis Olden ${ }^{2}$ and Afrooz Barnoush ${ }^{1}$ \\ ${ }^{1}$ Department of Mechanical and Industrial Engineering, Norwegian University of Science and Technology, Richard Birkelands vei 2B, \\ 7491 Trondheim, Norway \\ ${ }^{2}$ SINTEF Materials and Chemistry, 7456 Trondheim, Norway
}

\begin{abstract}
Fatigue crack growth (FCG) behavior of a Fe-3wt.\%Si ferritic alloy under different environmental conditions using in-situ electrochemical (cathodic) hydrogen $(\mathrm{H})$ charging has been investigated. Three frequencies have been applied. Results clearly show that the FCG rate increased by a factor spanning from 20 to 1000 times, depending on the loading frequencies, when compared to the reference test in air. Lower frequency leads to higher FCG rate. A comprehensive fractographic analysis was carried out: the area fraction of different fracture surface features was measured and taken into statistical analysis. Based on these investigations, the possible mechanisms of $\mathrm{H}$-enhanced FCG are discussed. Similar tests in high-pressure $\mathrm{H}$ gas from other studies were also compared and discussed. These results give a preliminary understanding of $\mathrm{H}$ effect in fatigue crack propagation procedure in ferritic alloys.
\end{abstract}

\section{Introduction}

It is generally acknowledged that engineering structures are normally experiencing different loads such as static load, cyclic load, impact load or a combination of several loads from the above-mentioned category. And a very common condition is cyclic loading combining a static loading. Researches regarding the fracture behavior from repeated loading have been published over a century and continue increasing. According to the data from Battele Laboratory under contract to United States Government agencies in 1983, the costs of fractures and efforts to prevent fracture amounted to 119 billion US dollars per year, which occupied a considerable part of the gross national product at that time [1]. It can be expected that this number becomes different today due to a faster development in industry. The classical fatigue crack growth behavior can be simplified by a logarithmic linear relation, which is called the Paris' law (or Paris-Erdogan law), as shown in Eq. (1):

$$
d a / d N=C \cdot \Delta K^{m}
$$

where $a$ is the crack length, $N$ is the number of cycles and $d a / d N$ is the crack growth rate, describing the infinitesimal crack length per increasing number of load cycles. $C$ and $m$ on the right-hand side are constants depending on material and test conditions. $\Delta K$ is the range of the stress intensity factor during fatigue loading, and is defined as Eq. (2):

$$
\Delta K=K_{\max }-K_{\min }
$$

where $K_{\max }$ and $K_{\min }$ are the maximum and minimum value of the stress intensity factor, respectively.

This relation is favored by many engineers since by taking a simple logarithmic operation, the crack growth rate and the stress intensity factor range can be treated as a linear relation, and it's easier for engineers to predict how fast the crack can grow without repairing it.

A factor that degrades the mechanical behavior of materials is the environmental effect, especially the environment containing hydrogen $(\mathrm{H})$, in which the materials can become more brittle than in other cases. This phenomenon is named hydrogen embrittlement (HE) and has been studied since the first publication by Johnson [2] in 1875. The HE effect of metallic materials has been intensively discussed over the past century. It draws engineers' attention since it can cause catastrophic failure of metallic structures that serve in a H-containing environment. Several different mechanisms have been developed, and the most common ones are hydrogenenhanced localized plasticity (HELP) [3-8], hydrogenenhanced decohesion (HEDE) [9-12], adsorptioninduced dislocation emission (AIDE) [13], hydrogenenhanced vacancy production $[14,15]$, hydrogeninduced phase transformation [16-18] etc. These mechanisms describe the HE effect in terms of different aspects ranging from chemical bonding up to microstructure level. A systematic review has been established by Murakami et al. [19] regarding the $\mathrm{H}$ effect on the fatigue crack propagation in steels.

For most oil and gas industries in the arctic region, the metallic structures will serve in a $\mathrm{H}$-containing environment (e.g. ocean) with a continuous vibrational loading. Hence the fatigue properties with environmental

Corresponding author: di.wan@ntnu.no

(C) The Authors, published by EDP Sciences. This is an open access article distributed under the terms of the Creative Commons Attribution 
effect of those structures are of significant importance. The purpose of this study is to study the mechanism in the degradation of structural materials that serve in the condition with cyclic loading and $\mathrm{H}$ environment and try to correlate the physical mechanism with engineering aspects. For this purpose, Fatigue Crack Growth Rate (FCGR) tests were done on a ferritic alloy with large grain size in different environments. The FCGR data were analyzed and correlated with the classical Paris' law. The results showed a strong effect of promoting crack propagation in $\mathrm{H}$ environment by a factor spanning from 20 to 1000 times. Scanning Electron Microscopy (SEM) characterization was done on the fractured specimens. The reasons for the degradation were discussed.

\section{Experimental}

\subsection{Materials}

The materials used in this study is a Fe-3wt.\%Si alloy with pure ferritic structure. The grain size of the asreceived material is about $300 \mu \mathrm{m}$. The chemical composition of this material is shown in Table 1.

Compact Tension (CT) specimens according to the ASTM E647 standard were cut from the raw material by Electric Discharge Machining (EDM). The geometry is shown in Figure 1.

Table 1. Chemical composition of the investigated material.

\begin{tabular}{c|c|c|c|c|c}
\hline Element & $\mathbf{C}$ & $\mathbf{S i}$ & $\mathbf{M n}$ & $\mathbf{P}$ \\
\hline wt.\% & 0.018 & 3.000 & 0.055 & 0.008 \\
\hline Element & $\mathbf{C u}$ & $\mathbf{A l}$ & $\mathbf{T i}$ & $\mathbf{N b}$ \\
\hline wt.\% & 0.013 & 0.015 & 0.001 & 0.002 \\
\hline Element & $\mathbf{S}$ & $\mathbf{C r}$ & $\mathbf{N i}$ & $\mathbf{M o}$ \\
\hline wt.\% & 0.003 & 0.010 & 0.006 & 0.003 \\
\hline Element & $\mathbf{V}$ & $\mathbf{B}$ & $\mathbf{Z r}$ & $\mathbf{F e}$ \\
\hline wt.\% & 0.001 & 0.0002 & 0.0010 & Bal. \\
\hline & & & \\
\hline
\end{tabular}

Figure 1. Schematic of the CT specimen (thickness $=8$, unit: $\mathrm{mm})$. SEM characterization was done on the fractured halfspecimen.

\subsection{Fatigue crack growth rate test}

The CT specimens were first pre-cracked by fatigue test by the same procedure as described in Ref.[20]. The final pre-cracks normally have a length ranging between 1 to $3 \mathrm{~mm}$. For the FCGR test, an initial stress intensity factor range $(\Delta K)$ corresponding to a $2.5 \%$ increase from the last $\Delta K$ value of the pre-crack test was applied. The fatigue crack growth rates and the crack length were recorded via an alternate current potential drop (AC-PD) device. The tests were done at room temperature in lab air and in an electrochemical cell. The frequencies were chosen to be $0.1 \mathrm{~Hz}, 1 \mathrm{~Hz}$ and $10 \mathrm{~Hz}$ and the load ratio $R$ was kept 0.5 during the test to reduce the crack closure effect.

For H-charging, the electrolyte was chosen to be a neutral $0.1 \mathrm{M} \mathrm{Na}_{2} \mathrm{SO}_{4}$ solution. The specimen was in-situ cathodically charged with a constant potential of -1400 $\mathrm{mV}_{\mathrm{SCE}}$. Multimeters were used during the charging procedure, to make sure the whole circuit runs as designed.

After tests, the specimens were put into liquid nitrogen and broken into two parts. The half-specimens were used for further characterization.

\subsection{Characterization}

For characterization, a Quanta 650 environmental scanning electron microscope (ESEM, Thermo Fisher Scientific Inc., USA) was used. The ESEM was operated at an accelerating voltage of $20 \mathrm{kV}$. To investigate the dislocation structure induced during the FCG test, electron channeling contrast imaging (ECCI) was performed on the cross-section of the fractured specimens. A solid-state four-quadrant backscatter electron (BSE) detector was used, and the contrast was controlled to an optimum state for dislocation imaging.

\section{Results}

\subsection{FCGR results}

The FCGR data is shown in Figure 2. It can be seen from the data that when $\mathrm{H}$ was applied, the crack propagation rate increased significantly. The enhancement depends strongly on the test frequency. When the frequency decreases, the crack propagation becomes faster. With the highest frequency $(10 \mathrm{~Hz})$ in the present study, the FCGR increased by about 20 times with respect to the test in lab air, while the lowest frequency $(0.1 \mathrm{~Hz})$ made the FCGR increase by about 1000 times. These data show a relatively good linear relation and were fitted by the Paris' law. The fitted parameters are shown in Table 2 . 


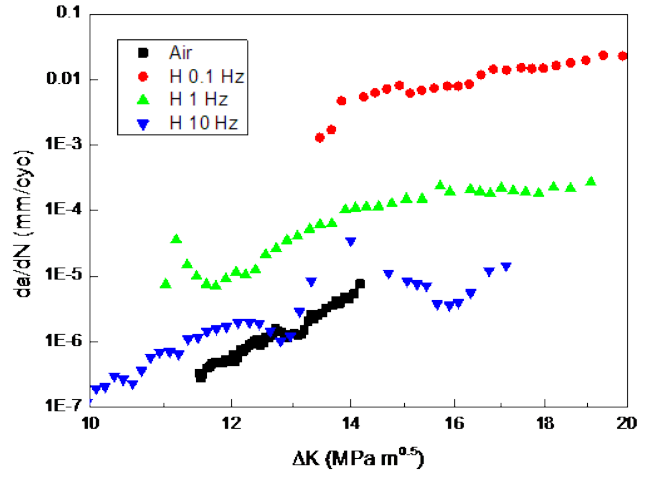

Figure 2. $d a / d N$ vs $\Delta K$ data for the studied specimens.

Table 2. Fitted parameters based on the Paris' law.

\begin{tabular}{|ccc|}
\hline Test condition & $C^{\prime}$ & $m^{\prime}$ \\
\hline $\mathbf{A i r}, \mathbf{R}=\mathbf{0 . 5}, \mathbf{f}=\mathbf{1 0} \mathbf{~ H z}$ & $3 \mathrm{E}-17$ & 7.890 \\
$\mathbf{H}, \mathbf{R}=\mathbf{0 . 5}, \mathbf{f}=\mathbf{1 0} \mathbf{~ H z}$ & $3 \mathrm{E}-15$ & 7.898 \\
$\mathbf{H}, \mathbf{R}=\mathbf{0 . 5}, \mathbf{f}=\mathbf{1} \mathbf{~ H z}$ & $5 \mathrm{E}-13$ & 6.986 \\
$\mathbf{H}, \mathbf{R}=\mathbf{0 . 5}, \mathbf{f}=\mathbf{0 . 1} \mathbf{~ H z}$ & $7 \mathrm{E}-9$ & 5.048 \\
\hline
\end{tabular}

\subsection{Fractography}

Fractography was taken on all half-specimens after the FCGR test. The fracture features were statistically analyzed. As shown in Figure 3a, the fracture surface of the specimens can be divided into three different regions, namely the EDM region, pre-crack region and the FCG region. It should be noted that the crack front was not necessarily a straight line due to non-uniform distribution of the stress field ahead of the crack tip. To avoid ambiguity between the pre-crack region and the FCG region, $1 \mathrm{~mm}$ was skipped from the measured starting place, and $0.6 \mathrm{~mm}$ was skipped from the edges through the thickness direction. As a result, only the highlighted part in Figure 3a was considered in the statistics. For fracture features, normally three distinct features can be identified, namely transgranular (TG) type, intergranular (IG) type and the so-called "quasicleavage" ("QC") type, as shown in Figure 3b-d. The area percentage of each fracture mode was analyzed on all $\mathrm{H}$-charged specimens from the fractography, and the result is shown in Figure 4. The specimen tested in air showed only TG fracture and a minor percentage of IG fracture over the tested $\Delta K$ range. It should be noted that the name of "QC" fracture is somehow ambiguous, but it has been such named in many literature regarding crack growth with $\mathrm{H}$ environment (e.g. $[8,15,21,22])$ and we just keep the convention. It can be seen from the results that $\mathrm{H}$ mainly changes the relative amount between TG and "QC" fracture modes. When $\mathrm{H}$ is charged to the specimen, "QC" fracture starts to happen to the material. When the frequency decreases, the "QC" percentage increases and the TG percentage decreases, with minor change in the IG percentage.

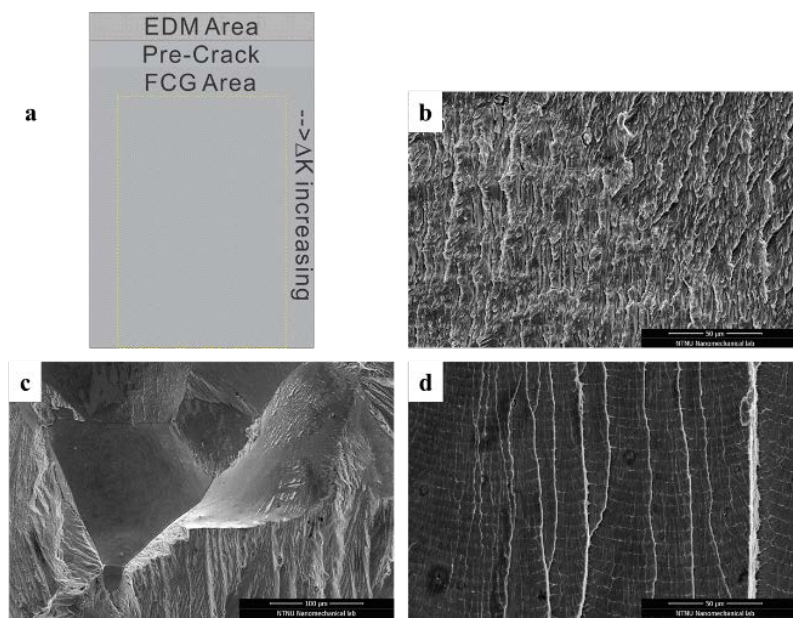

Figure 3. a. schematic description of the statistical analysis; $b$. typical TG fracture; c. typical IG fracture; d. typical "QC" fracture.

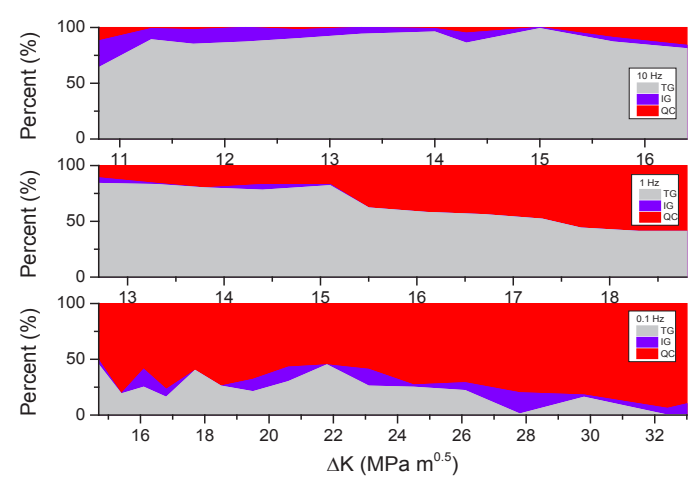

Figure 4. Fracture mode distribution with respect to $\Delta K$ level.

Images with high magnification were taken regarding each fracture feature on specimens tested in all conditions. The results are shown in the following figures.

In the TG fracture zone (as shown in Figure 5), the structures are similar in $\mathrm{H}$-free and $\mathrm{H}$-charged cases. Small and fine striations that are almost vertical to the global crack growth direction could be observed over the fracture surface. Tear edges are commonly observed, and the striations are normally vertical to the direction of the tear edges.

Figure 6 shows the magnified IG fracture surface. The figures show clearly fracture following grain boundaries (GBs), leaving a smooth surface from the boundaries without visible striations. There is not much different between the $\mathrm{H}$-free and all the $\mathrm{H}$-charged conditions. It is worth noting that the IG fracture type occupies only a small fraction according to the statistics in Figure 4.

Figure 7 shows the "QC" fracture in all conditions. Sparsely distributed brittle-like striations that are almost perpendicular to the global FCG direction could be observed on the surfaces. In the H-charged cases the fracture left sharp edges on the surface, and the striations were faceted in all $\mathrm{H}$-cases. River-lines are visible on the fracture surfaces, and the lines are more or less parallel 
to the global FCG direction. It is important to be pointed out that the "QC" feature could not be observed in the air case. Figure 7a shows the most similar feature in air as "QC" in H-cases, but the striations are not faceted and the tear ridges are not as sharp as the H-cases. The "QC" feature is characteristic from the $\mathrm{H}$ influence.

\section{3. $\mathrm{ECCl}$ characterization}

Preliminary ECCI characterization was performed on the cross-section of the fractured specimen to investigate the dislocation structures below the fracture surface. The result is shown in Figure 8. The global FCG direction is from left to right, but local variations could be observed. Plastic zones can be identified by the bright contrast due to a high dislocation density. The bright contrast above the yellow dash-line in Figure $8 \mathrm{a}$ comes from Fecoating. Away from the plastic zone, sparsely distributed dislocations were observed in the $\mathrm{H}$-free case, while in the H-charged case, dislocations were better organized into vein-like structures. This is the preliminary result and further systematic and detailed work is ongoing.
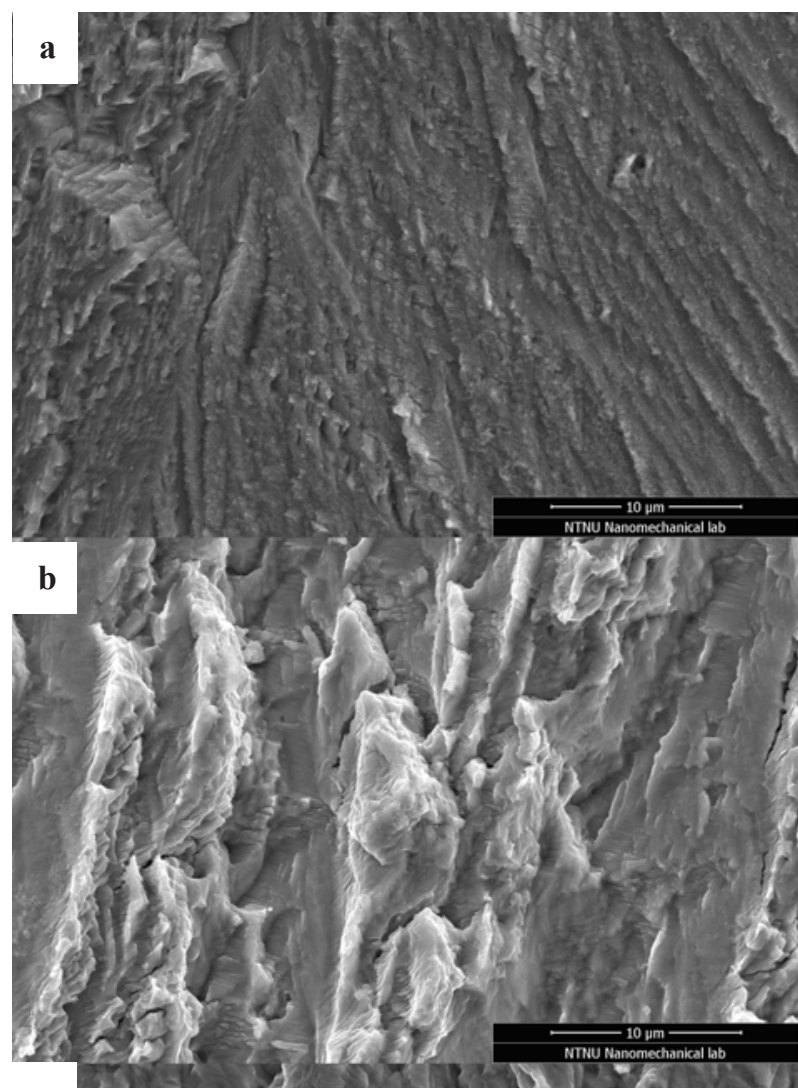

b

c

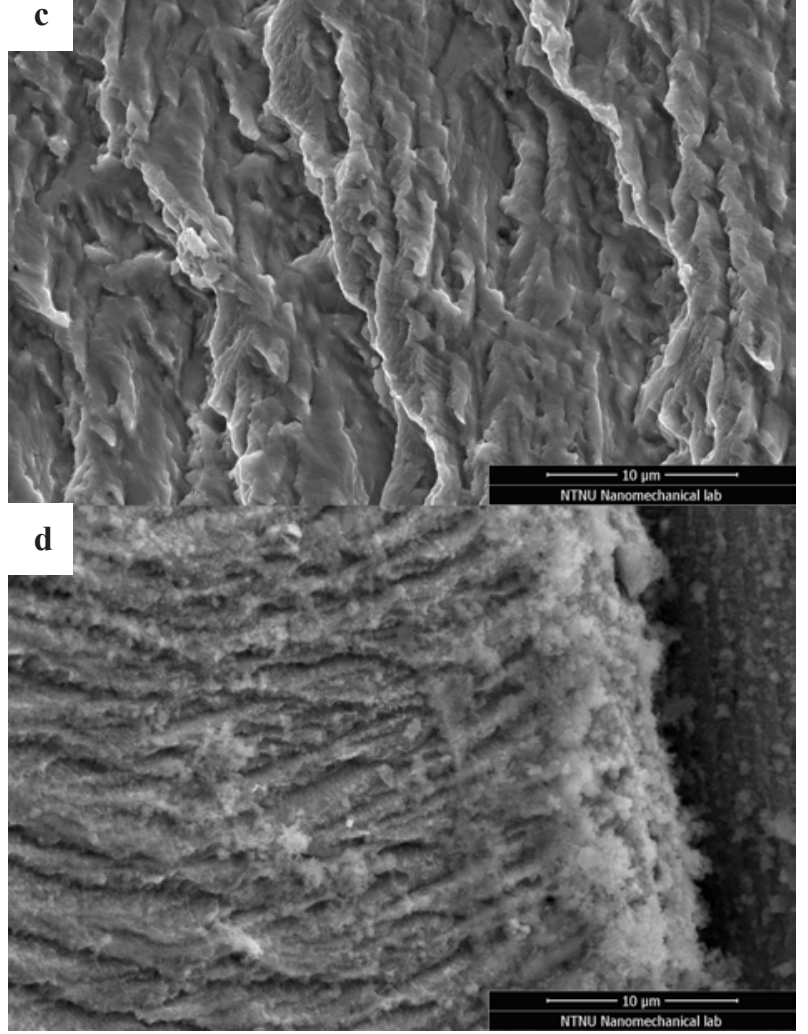

Figure 5. Magnified images showing structure in TG fracture region (a. in Air; b. in $\mathrm{H}, \mathrm{f}=10 \mathrm{~Hz}$; c. in $\mathrm{H}, \mathrm{f}=1 \mathrm{~Hz}$; d. in $\mathrm{H}, \mathrm{f}$ $=0.1 \mathrm{~Hz}$; global FCG direction from top to bottom for each case) 
$\mathbf{a}$

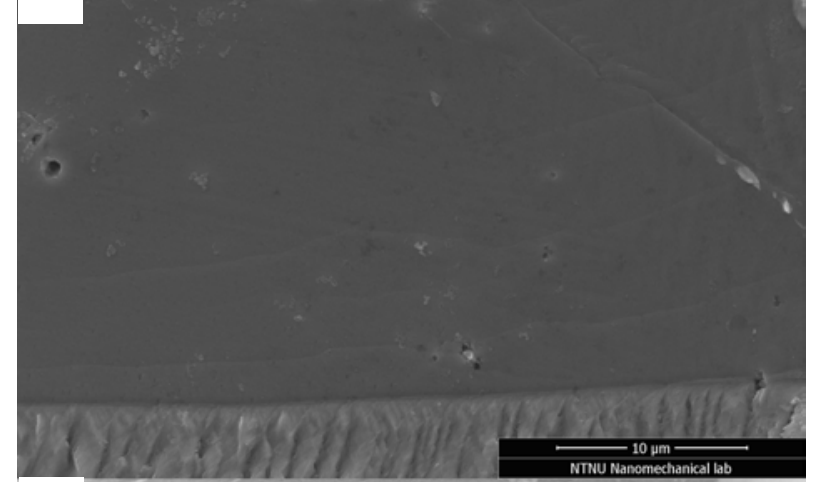

$\mathbf{b}$

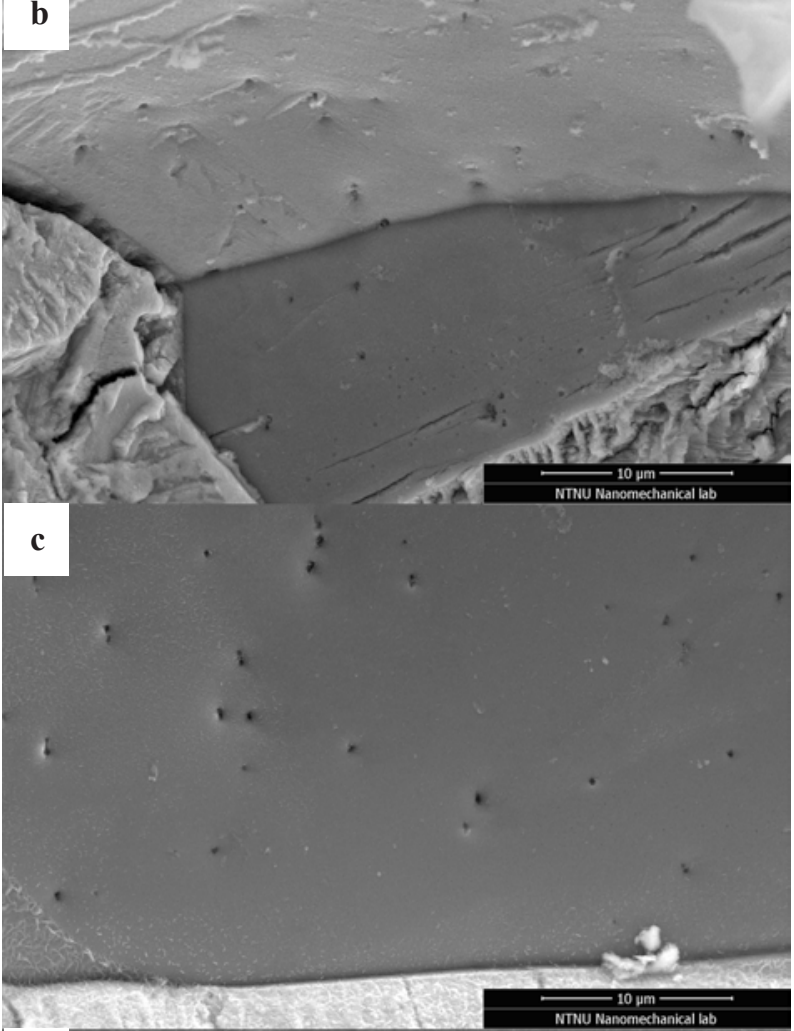

d

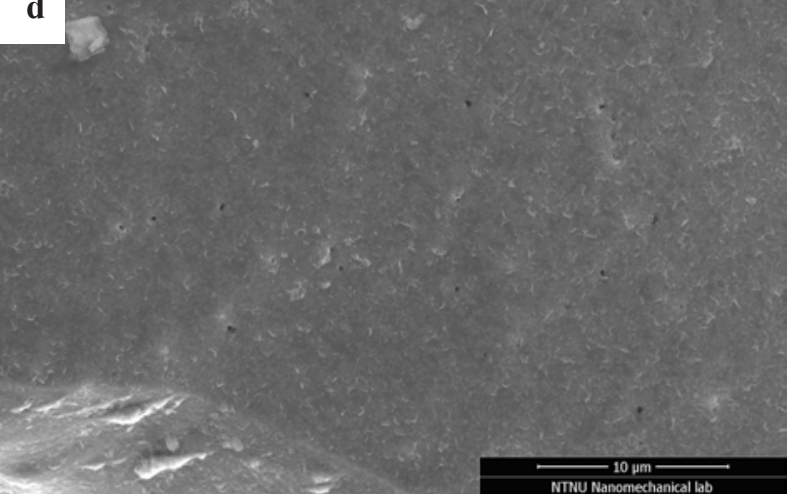

Figure 6. Magnified images showing structure in IG fracture region (a. in Air; b. in $\mathrm{H}, \mathrm{f}=10 \mathrm{~Hz}$; c. in $\mathrm{H}, \mathrm{f}=1 \mathrm{~Hz}$; d. in $\mathrm{H}, \mathrm{f}$ $=0.1 \mathrm{~Hz}$; global FCG direction from top to bottom for each case)

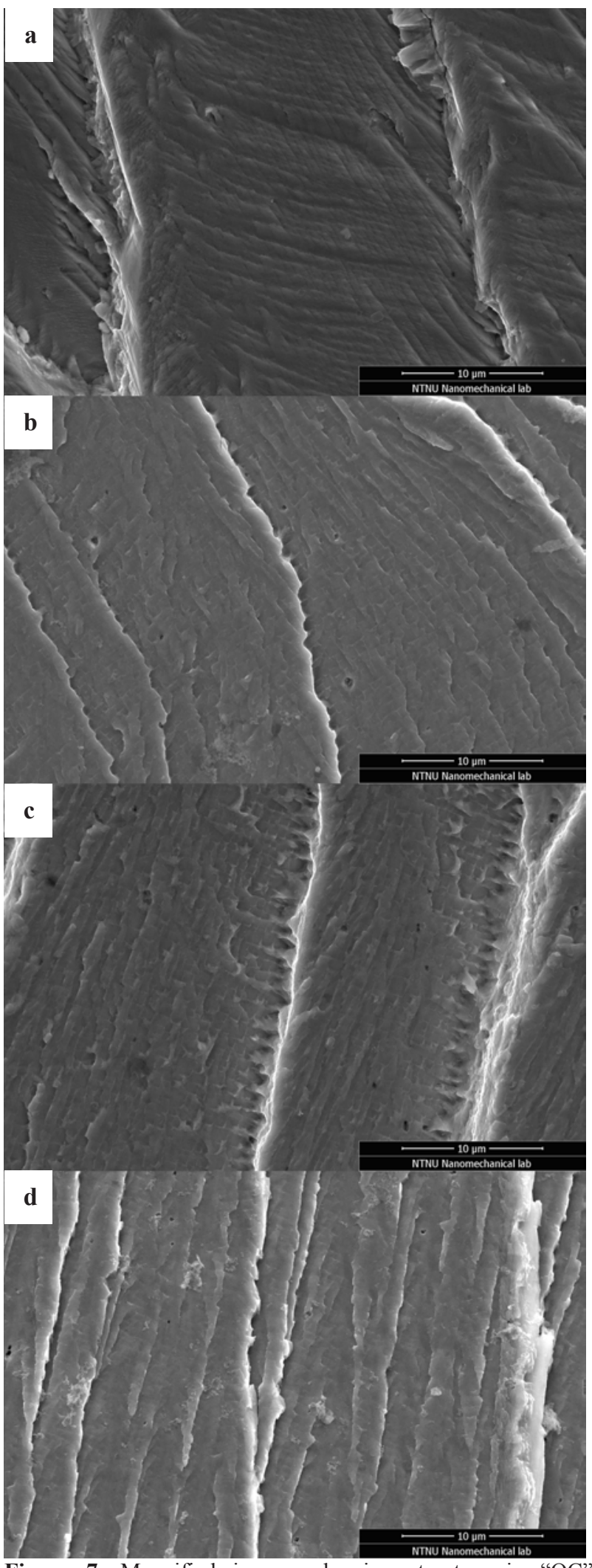

Figure 7. Magnified images showing structure in "QC" fracture region (a. in Air; b. in $\mathrm{H}, \mathrm{f}=10 \mathrm{~Hz}$; c. in $\mathrm{H}, \mathrm{f}=1 \mathrm{~Hz}$; d. in $\mathrm{H}, \mathrm{f}=0.1 \mathrm{~Hz}$; global $\mathrm{FCG}$ direction from top to bottom for each case) 

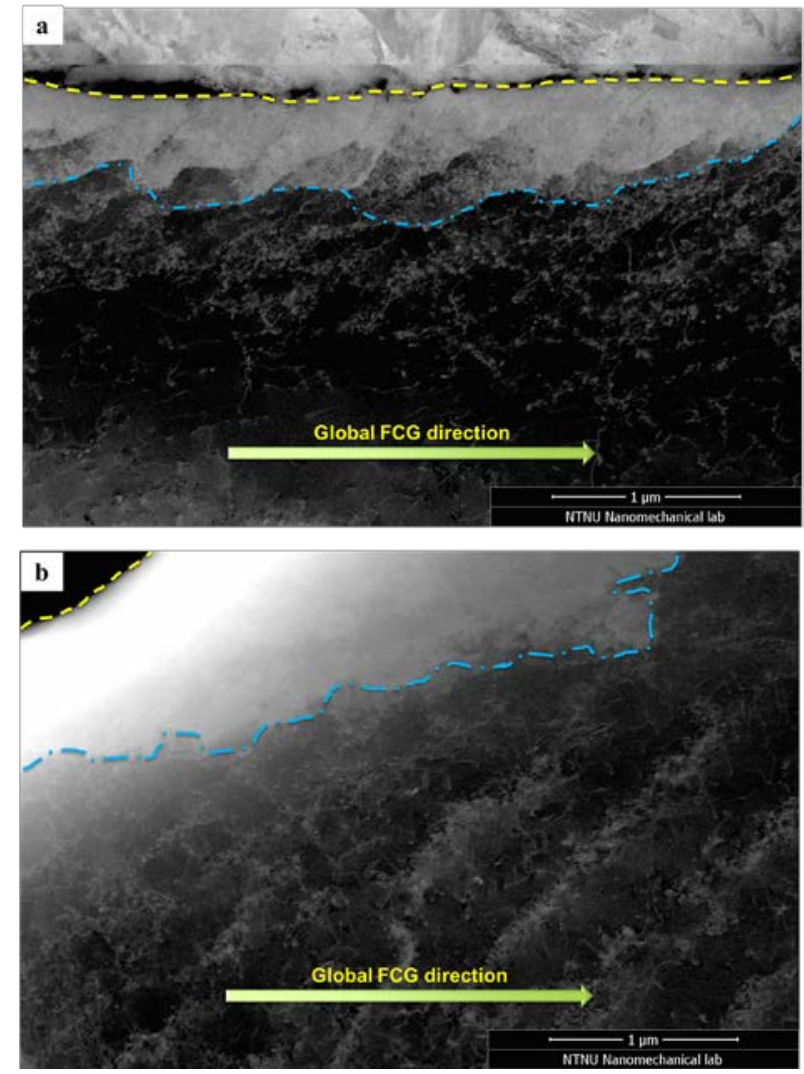

Figure 8. Dislocation structures observed by ECCI in a. H-free case and $\mathrm{b}$. H-charged case from the region fractured at similar $\Delta K$ level. The yellow dash-line is the fracture surface and the light blue broken-line is the indicated plastic zone under the fracture surface.

\section{Discussion}

\subsection{Paris' relation}

It is clearly shown that the measured crack growth data can be properly correlated with the Paris' law. This relation can describe the crack growth procedure in a mathematically simple and linear relation, also when aggressive environment applies. These data show that the Paris' law is validated for these test conditions. However, the local variation in different grains or different fracture features can give error in the estimation. A systematic verification at the microscale level is ongoing. This will be analyzed and discussed in a future work by the present authors.

\section{2 $\mathrm{H}$ effect on FCG procedure}

It is clearly shown in the crack growth data that when $\mathrm{H}$ was charged, the crack growth rate was increased up to 1000 times in comparison with the reference test in air. The test frequency also played a significant role in the crack growth rate enhancement. It could be inferred that the $\mathrm{H}$ degradation is a time-dependent process. When the frequency decreases, $\mathrm{H}$ has more time to invade the lattice and deteriorate the mechanical behavior, globally makes the crack grows faster. Chen et al. [23] also suggested that the $\mathrm{H}$-assisted cracking is time-dependent in $\mathrm{Fe}-3 \% \mathrm{Si}$ single crystals.

From the statistics in Figure 4, the frequency also influences the fracture mode distribution. A higher frequency leads to more $\mathrm{TG}$ fracture and a lower frequency gives more "QC" fracture, with the IG fraction almost keeps unchanged. The possible reasons might be that the "QC" fracture was transformed from the TG fracture by the effect from $\mathrm{H}$.

Matsuoka et al. [24, 25] has explained the formation of this fracture feature in terms of reduced plasticity expansion in the crack-tip region. Based on their model, these striations are the results from slip localization, which is compatible with the HELP mechanism [3, 4]. They suggested that when the cyclic load was exerted to the specimen, the stress would be localized in the vicinity of the crack-tip, and the $\mathrm{H}$ atoms would be attracted by the highly localized tensile stress field. The localized $\mathrm{H}$ concentration made the crack propagation much easier even at a lower stress level during unloading procedure. Consequently, the distances between striations are larger in the $\mathrm{H}$-charged specimens than the one tested in air. Similar features have also been observed in polycrystalline pure iron [22] and $\mathrm{Fe}-\mathrm{Si}$ single crystals $[26,27]$ with $\mathrm{H}$ influence.

Another key point from Figure 4 is that when $\Delta K$ level increases, there is always a tendency of increasing "QC" fraction and decreasing TG fraction. This is the most significant for $1 \mathrm{~Hz}$, but a clear tendency is also seen for $0.1 \mathrm{~Hz}$ and $10 \mathrm{~Hz}$. Since "QC" feature is characteristic for the $\mathrm{H}$ influence, we can assume the fraction of "QC" fracture is a factor that can give an estimation of the HE level. Since the HE happens generally in high strength materials, it is suggested that the combination of high stress level and high $\mathrm{H}$ concentration makes the embrittlement possible. During FCGR tests, there is always a stress concentrated zone ahead of the crack-tip, which can also attract $\mathrm{H}$ atoms and enhance the local $\mathrm{H}$ concentration.

\subsection{Dislocation structure}

The ECCI results shown in Figure 8 are some preliminary results from dislocation investigations. The regions of interest came from a similar $\Delta K$ level during the FCGR tests. The H-case shows highly organized vein-like dislocation structure while the $\mathrm{H}$-free case does not show similar feature. This could be the effect from $\mathrm{H}$ that dislocations were localized along some specific crystallographic directions, while impeded in other directions. As a result, concentration to some organized structures. However, there are some points still remain unclear such as the grain orientations, the accommodation from nearby grains, the local stress field, etc. Further investigations are ongoing and will be discussed more in detail in a future work by the present authors.

Nevertheless, some proof could be found from literature. For example, Wang et al. [8] did a similar work on pure iron with the help of scanning transmission electron microscope (STEM). It has been explained in this work 
that the attachment of $\mathrm{H}$ to dislocations or other obstacles will change the stress field associated with crystallographic defects, and consequently enhancing the dislocation motion preferred in some specific directions while suppressing in other directions. As a result, the observed dislocation structure should be more organized in the $\mathrm{H}$-charged case than that from the $\mathrm{H}$-free case.

\section{Conclusions}

In this study, the fatigue crack growth behavior of a ferritic Fe-3wt.\%Si alloy was tested both in lab air and with in-situ cathodic H-charging. Post-mortem fractography analysis was done through SEM. The main results can be summarized in the following points:

- The FCGR is increased by in-situ cathodic Hcharging by a number ranging from 20 to 1000 times in comparison with a reference test in air;

- The higher crack growth rate is attributed to the increasing proportion of the "QC" type fracture, and it depends on the loading frequency and $\Delta K$ level;

- IG fracture occupies only a small part in comparison with TG type and "QC" type. GBs are not preferred crack propagation path;

- The preliminary investigations on dislocation structures show difference in $\mathrm{H}$-free and $\mathrm{H}$ charged cases, and more detailed systematic work is ongoing.

This work is financially supported by the Research Council of Norway through the HyF-Lex project (Petromaks 2 Programme, Project Number: 244068/E30).

\section{References}

[1] P. Peralta, C. Laird, Fatigue of Metals, in: D.E. Laughlin, K. Hono (Eds.), Physical Metallurgy (Fifth Edition), vol 2, Elsevier, Amsterdam, (2014), pp. 17651880.

[2] W.H. Johnson, P R SOC LONDON 23 (1875) 168179.

[3] C.D. Beachem, METALL MATER TRANS B 3 (1972) 441-455.

[4] H.K. Birnbaum, P. Sofronis, MAT SCI ENG A 176 (1994) 191-202.

[5] I.M. Robertson, ENG FRACT MECH 64 (1999) 649673.

[6] I.M. Robertson, H.K. Birnbaum, ACTA METALL 34 (1986) 353-366.

[7] I.M. Robertson, H.K. Birnbaum, P. Sofronis, Hydrogen Effects on Plasticity, vol 15, (2009), pp. 249293.

[8] S. Wang, A. Nagao, P. Sofronis, I.M. Robertson, ACTA MATER 144 (2018) 164-176.
[9] W.W. Gerberich, P.G. Marsh, J.W. Hoehn, Hydrogen Induced Cracking Mechanisms - Are There Critical Experiments?, in: A.W. Thompson, N.R. Moody (Eds.), Hydrogen Effects in Materials, Minerals, Metals \& Materials Society (TMS), Warrendale, Pennsylvania, USA, (1996), pp. 539-554.

[10] R.A. Oriani, CORROSION 43 (1987) 390-397.

[11] R.A. Oriani, P.H. Josephic, ACTA METALL 25 (1977) 979-988.

[12] R.P. Gangloff, Environment-Induced Cracking of Materials 1, (2008) 141-165.

[13] S.P. Lynch, ACTA METALL 36 (1988) 2639-2661.

[14] Y. Fukai, J ALLOY COMPD 356-357 (2003) 263269.

[15] M. Nagumo, MAT SCI ENG 20 (2013) 940-950.

[16] H.K. Birnbaum, J LESS COMMON METALL 104 (1984) 31-41.

[17] N. Narita, C.J. Altstetter, H.K. Birnbaum, METALL TRANS A 13 (1982) 1355-1365.

[18] D.S. Shih, I.M. Robertson, H.K. Birnbaum, ACTA METALL 36 (1988) 111-124.

[19] Y. Murakami, R.O. Ritchie, Effects of hydrogen on fatigue-crack propagation in steels, Gaseous Hydrogen Embrittlement of Materials in Energy Technologies, vol 2, Woodhead Publishing, (2012), pp. 379-417.

[20] A. Alvaro, O.M. Akselsen, X. Ren, P.-A. Kane, Fatigue Properties of a $420 \mathrm{MPa}$ Structural Steel at Low Temperature, The 25th International Ocean and Polar Engineering Conference, vol 4, Kona, Big Island, Hawaii, USA, 2015, pp. 331-337.

[21] Y. Ogawa, H. Matsunaga, J. Yamabe, M. Yoshikawa, S. Matsuoka, I J FATIGUE 103 (2017) 223233.

[22] Y. Ogawa, D. Birenis, H. Matsunaga, A. Thøgersen, Ø. Prytz, O. Takakuwa, J. Yamabe, SCR MATER 140 (2017) 13-17.

[23] X. Chen, W.W. Gerberich, METALL TRANS A 22 (2012) 59-70

[24] S. Matsuoka, H. Tanaka, N. Homma, Y. Murakami, I J FRACT 168 (2010) 101-112.

[25] S. Matsuoka, N. Tsutsumi, Y. Murakami, T JAP SOC MECH ENG A 74 (2008) 1528-1537.

[26] H. Vehoff, P. Neumann, ACTA METALL 28 (1980) 265-272.

[27] H. Vehoff, W. Rothe, ACTA METALL 31 (1983) 1781-1793. 